\title{
Teachers' strategies for teaching pupils with reading difficulties: The case of Awutu Senya East Municipality, Central of Ghana
}

\author{
Nsenyiane, Anthony Mensah \\ Dambai College of Education, Ghana (tonybrown2014@yahoo.com) \\ Amaniampong, Philemon $\square$ \\ Methodist College of Education, Ghana (philemonamaniampong@yahoo.com)
}

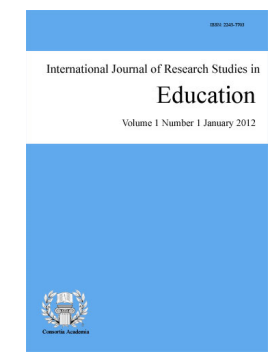

ISSN: 2243-7703 Online ISSN: 2243-7711

OPEN ACCESS

\section{Abstract}

The purpose of the study was to explore the strategies teachers use in teaching reading to 5 pupils with reading difficulties in the Awutu Senya East Municipality, Central Region, Ghana. It followed a mixed method approach. A sample size of 50 teachers was used for the study. To obtain a representative sample of the population of the teachers, the simple random and purposive samplings were used in selecting teachers from three basic schools in the Awutu Senya East Municipality. Data were collected through questionnaire and interview. Qualitative data were obtained through focus group interview with the teachers while quantitative data were obtained through administration of teacher questionnaire. The data on the subscales were entered into SPSS version 21.0 to compute Cronbach's Alpha co-efficient in order to determine the internal consistency of sub-scales. The final stage of analysis involved the identification and interpretation of the dominant themes in the strategies teachers use in the schools. The findings of the study revealed that teachers used language experience approach, phonemic awareness instruction, peer reading, comprehension instruction, reading aloud and motivation in helping pupils with reading difficulties to improve on their reading skills. The study recommended that more workshops focusing on reading strategies should be organized by the Ghana Education Service for teachers to update the existing strategies they use.

Keywords: reading, strategies, reading difficulties, phonemes, approach 


\section{Teachers' strategies for teaching pupils with reading difficulties: The case of Awutu Senya East Municipality, Central of Ghana}

\section{Introduction}

Reading is the ability to understand printed materials. Reading helps one to find information for him or herself, opens his or her mind, makes one happy in terms of overcoming loneliness and frustration, and offers one's lifetime employment. Baatjies (2003) asserted that the most important element of high quality education is literacy and that without the ability to read, learners are denied an important process of information on a variety of issues, as well as sources of pleasure and enrichment.

Reading, like all skills, is developed and refined through practice. A budding reader requires certain knowledge of skills that places that reader in a specific stage of reading development (Walker, 2008). Skills are processes that readers use habitually; therefore, practice activities must be identified and planned so that readers can complete them with speed, fluency and accuracy (Temple, Ogle, Crawford, \& Freppon, 2008). Temple et al. (2008) explained that, if reading skills are designed to fit their weaknesses, then it is likely that readers will be practicing slow, non-fluent, inaccurate reading and will be learning to read in that manner. To Temple et al., teachers should specifically select reading materials so that readers encounter little difficulty understanding the material, plan skill activities so that readers can achieve with them, plan alternative strategies for all activities, and when the readers stall on an activity, help them immediately or initiate other activities and encourage them to make decisions, whenever possible. In the opinion of these authors, students are likely to pick activities that are of most interest to them and those that they can complete successfully. Taylor (2007) argued that reading is essential to students' success in school and, ultimately, to their success in life. Taylor further maintained that struggling readers are certainly at a disadvantage when they cannot construct meaning from a text. He indicated that, when students get off to a poor start in reading, they hardly catch up. In addition, struggling readers encounter negative consequences, and as they progress through the grades, the academic distance from those who read well grows more pronounced.

Fitzpatrick, McLaughlin and Weber (2004) found that combining direct instruction with the methodology of precision teaching in reading instruction is an effective strategy for improving pupils' reading skills. In addition, they found that combining these two data-based and effective teaching strategies can improve the academic skills of a wide range of students, including those with disabilities.

Sunjoo (2013) examined the impact of Transactional strategy instruction (TSI) on the reading comprehension of a diverse group of 29 second graders in San Francisco. Sunjoo adopted a combined-methods study, consisting of both teacher action research (TAR) and participatory action research (PAR) with an interview guide as an instrument for data collection. The findings of the study indicated that TSI was effective with students in the primary grades, such as second grade, in teaching reading comprehension and in increasing autonomy in children. The study concluded that there was an interaction among various factors found as the result of Literature Circles such as reading comprehension, autonomy, motivation and enjoyment, children helping each other, children informing instruction for the teacher. Sunjoo suggested that alternative paradigms in teaching and research such as Literature Circles and PAR are in need in the primary grades.

Boison (2008) noted that the language experience approach is based on children's language and experiences. Tompkins (2001) indicated that, in this approach, children dictate words and sentences about the experiences, the teacher writes down what the children say, and then the text they develop becomes the reading material. Walker (2008) added that, the language experience approach is a technique used for beginning reading instruction in which the child dictates a story to the teacher. The story becomes the text for instruction, and a collection of the stories becomes the child's first reader. 
Mensah (2014) investigated the use of the language experience approach at La Anglican Basic School in Accra, Ghana. A sample of 52 pupils, comprising 23 girls and 29 boys, was used for the study. The findings of the study showed that the experimental class performed significantly better than the control class. According to the results of the study, the use of the language experience approach, thus, improved the reading skills of pupils and might, therefore, have some advantage over the traditional way of teaching reading. Adler (2001) states that phonemic awareness is the ability to notice, think about, and work with the individual sounds in spoken words. To Adler, before children learn to read prints, they need to become aware of how the sounds in words work. He argues that children must understand that words are made up of speech sounds or phonemes.

Boison (2008) found that phonemic awareness instruction improves children's ability to read words. It also improves their reading comprehension. To Boison, phonemic awareness instruction aids reading comprehension primarily through its influence on words reading. In the author's opinion, for children to understand what they read, they must be able to read words rapidly and accurately. According to her, rapid and accurate word reading frees children to focus their attention on the meaning of what they read. While, Carnine, Silbert, Kame'enui, and Tarver (2004) stated that phonics instruction teaches the relationship between the letters of written language and the individual sounds of spoken language. To them, it also teaches how these relationships are used to read and write words. Carmine et al. maintained that the following terms have been used to refer to these relationships: letter-sounds association, letter-sound correspondences, sound-symbol correspondences, sound-spelling, grapheme-phoneme correspondences, and graph-phonemic relationship. To them, the goal of phonics instruction is to help children to learn and use the alphabetic principle - the understanding that the written letters correspond to spoken sounds and that the correspondences are systematic and predictable. In their opinion, the knowledge of the alphabetic principle helps children to recognize familiar words accurately and automatically, and decode new words independently.

Focusing on phonics instruction for at-risk third graders, Rowe (2013) adopted the case study design using an observation with the population of 107 students. The results indicate a significant relationship between continued phonics instruction and success on the OAA for two out of five years, and demonstrate the positive effect of explicit, systematic phonics instruction on reading achievement. In another study conducted by Phipps (2011) on phonics instruction, Phipps adopted the quantitative research approach with 39 students using pre-test and post-test as an instrument for the data. The results of the study indicated that all students receiving intervention showed statistically significant gains in their ability to decode phonetically correct words, suggesting that targeting specific sounds is an effective strategy, even for older students.

A study by Guthrie, Wigfield, Metsala, and Cox (2009) on third- and fifth-graders, and eighth- and 10-graders found connections between the amounts of time spent reading and comprehension, and between the motivation to read and the time spent reading. After statistically controlling for reading achievement, prior topic knowledge, self-efficacy, and reading motivation, the study of third- and fifth-graders showed reading motivation significantly predicted the amount of reading. The study of older students (after similar statistical controls were imposed) found that, as with the younger group, motivation predicted both the amount of time spent reading, and the amount of time spent reading significantly predicted text comprehension.

Peer tutoring is a practice that can allow classroom teachers to cater for diverse needs within an inclusive context and there is a wide range of studies supporting its effectiveness (Frederickson \& Cline, 2002). Peer tutoring and cross-age tutoring are instructional methods in which students help each other to learn and, in turn, learn by teaching. One child acts as the tutor while the other is the learner or tutee. Peer tutoring involves learners of the same age helping their peers while cross-age tutoring involves students from older classes helping younger children. This approach has well documented academic and social benefits for both the tutor and the learner (Hayford, 2013). Peer tutoring has also been shown to improve self-esteem and social interactions. Another benefit of peer tutoring is that it frees up teachers by giving them time to provide more direct support to individual pupils/students, particularly those who record lower attainments. Peer tutoring is also relatively easy to implement. Peer tutoring takes time and care to set up properly but pays huge dividends. Hayford (2013) explained 
that ideal peer tutoring tasks include reviewing previously learned skills, practicing, and building fluency and direct instruction in new skills and concepts.

A well-organized peer tutoring system can facilitate access and participation in a variety of ways; for example, it can be used to deliver individual support and facilitate curriculum access for new students learning English as an additional language (Curtis, as cited in Hayford, 2013). Frederickson and Cline (2002) suggested that this may be a particularly helpful approach when peer tutors are drawn from those who speak the same first language. Studies have also shown that this approach is particularly helpful for pupils with disabilities when they adopt the role of tutor (Vaughn, Gersten, \& Chard, 2000; Wilson, 2003). It also offers a valuable means of involving pupils with special educational needs in natural social networks both within and beyond the class (Riddell, Tisdall, \& Mulderrig, 2006). Peer tutoring programs are designed for students to tutor one another through a tutor/teacher relationship. Often the roles are reversed in a strategy called reverse-role tutoring. Although little research had been found with reverse-role tutoring, students have illustrated benefits: the student's abilities rather than disabilities are highlighted (Tournaki \& Criscitiello, 2003). To Tournaki and Criscitiello (2003), peer tutoring allows for immediate corrective feedback, allowing for an increase in understanding from the text.

A research conducted by Rohrbeck, Ginsburg-Block, Fantuzzo, and Miller (2003), in a meta-analysis of 81 peer tutoring studies in elementary school, found a positive 0.33 effect size for peer tutoring compared to control groups. Their study further revealed that peer tutoring has also penetrated a broad range of educational practices. Sutherland and Snyder (2007) used peer-tutors to improve the reading skills of middle school students with emotional and behavior disorders. The study revealed that classroom disruptive behaviors decreased simultaneously as academic gains were made. Also, the students reported to have enjoyed the peer-tutoring program. This discussion, therefore, motivated me to examine the strategies teachers use in helping pupils with reading difficulties in the Awutu Senya East Municipality in the Central Region, Ghana.

\section{Methods}

The study adopted the mixed method approach to explore the strategies teachers use in helping pupils with reading difficulties in the Awutu Senya East Municipality in the Central Region of Ghana. The accessible population for the study was 85 participants from the three selected cluster of schools in the Awutu Senya East Municipality. A sample size of 50 teachers was involved in the study. This was made up of 15 teachers from Odupongkpehene cluster of schools, 20 teachers from Akweley cluster of schools and 15 teachers from Ofaako cluster of schools. The reason for choosing the simple random sampling was that the larger the sample, the more closely it will mirror the percentages in the overall population. The teachers were, thus, randomly chosen for the study. The aim was that, having been in the schools for that period 10 years, they might have identified pupils with reading difficulties in their classrooms. The teachers were also chosen because they had been teaching and working with pupils with reading difficulties on a daily basis and could share the provisions they made in teaching reading to the pupils with reading difficulties to improve on their reading skills. The purposive sampling was used to increase the utility of data obtained from the small samples. It was also used to select teachers who had been teaching reading to the pupils for a long time. The teachers were also in a good position to tell the strategies they made in teaching reading to pupils with reading difficulties. Consequently, all teachers willing to be interviewed were handpicked to take part in the study.

To collect data for the study, questionnaire and interview guides were used as instruments to gather data. A questionnaire is a prepared form comprising a set of questions administered to respondents to elicit information for the study. The questionnaires were administered personally by the researcher to the participants in their respective schools after permission was obtained and issues concerning the study were explained to them. The respondents were given one week to complete the questionnaires and I subsequently went to collect them. The reasons for the one week was to enable the respondents to complete the questionnaire in private, to devote as much time as they wished to its completion, to be in familiar surroundings, and to avoid the potential threat or pressure to participate as a result of the researcher's presence. At the end, all the questionnaires were answered

28 Consortia Academia Publishing (A partner of Network of Professional Researchers and Educators) 
and submitted to the me.

Focus group interactions were adopted to elicit data for the study from the teachers. Focus group interview is a face-to-face encounter between the researcher and participants with the focus on finding out their perspectives on their lives, experiences or situations as expressed in their own words on the main variables raised in each of the research questions (Taylor \& Bogdan, as cited in O'Donoghue, 2007). In the focus group, a semi-structured interview guide was used. The questions were phrased to allow unique responses from each interviewee as suggested by Macmillan and Schumacher (2001). The items were designed and reflected on the key issues raised in the research questions.

The focus group interview enabled the participants to tell their own experiences. Every word that people use in telling their stories is a microcosm of their consciousness (Greef, 2005). Focus group interviews can, however, pose challenges to interviewer who lacks control over the interview discussion. As a result of this, each focus group was limited to at most four teachers in order to have control over their interactions. Also, when focus group interviews are audio-taped, transcriptions and distributed from the voices of individuals in the group may be difficult. Taking notes becomes difficult because so much is occurring (Creswell, 2012). To eliminate this, each teacher was allowed to identify him/herself before responding to a question.

The focus group interactions also allowed for probing and clarification of issues, as well as offered the greatest scope and depth of investigation to examine the provisions teachers make in teaching reading to pupils with reading difficulties.

\subsection{Procedure for data collection}

The questionnaires were administered personally by the researcher to the participants in their respective schools after informed consent was obtained from the authorities of the school prior to the commencement of the study. This was facilitated by an introductory letter formally submitted to the head teacher of the school indicating the purpose of the study. A familiarization visit was done to the school to book appointments with school authorities and teachers. The appointments were made such that it was possible to meet the teachers that were involved in the study. In addition to the letter, the researcher explained the purpose of the study to the participants and informed them that the finding of the study was purely an academic work. The researcher further explained why their schools were chosen and detailed how much time would be spent at the school. They were duly informed that their participation was voluntary and were free to abstain or even withdraw from the study, if they felt so.

A focus-group interview guide was used to gather information from teachers. The focus group interview comprised of (4) members from each selected school and lasted for 45 minutes each. The focus-group interview was crucial to the study because it gave room for direct interactions with the teachers. The focus-group interviews were conducted in a narrative way to allow the teachers to express themselves in a comfortable way. The researcher gave a list of questions on a semi-structured interview guide but the teachers were allowed to lead the discussion. The interview was audio-taped and transcribed after permission was obtained from the teachers. After each session, the recorded interviews were played back to the interviewees to validate the contents as a true reflection of what had transpired during the interviews.

\subsection{Data analysis}

Data collected from questionnaires and interview guide were carefully organized and analyzed. Data in this study were analyzed quantitatively and qualitatively. Qualitative analysis involved making inferences and conclusions from teachers' responses from the focus-group interviews. Quantitative data were derived from the questionnaires using the Statistical Package for Social Sciences (SPSS). Descriptive statistics for each scale and summary were compiled. The results were presented in the form of frequencies, percentages, means and tables. 
The interview was conducted within the school premises using a semi-structured interview guide. The main procedure for conducting the interviews was through the use of tape recorders and each interview lasted between for 45 minutes. With this, the teachers were assured the necessary confidentiality throughout and permissions were sought to use a tape-recorder.

Analysis of the interview data was guided by key themes that emerged from the data. The process started with transcribing all interviews and highlighting words, sentences, and thoughts that served as units for more detailed coding. Using the interview transcriptions, the data were analyzed using a three-tiered procedure for open, axial, and selective coding processes.

\subsection{Ethical consideration}

De Vos, Strydom, Fouche, and Delport (2005) argued that ethics in research are important in ensuring the humane treatment of participants in the research. Three of the ethical considerations, informed consent, anonymity and confidentiality, were important to this study. In this study, an informed consent meant that those interviewed had given their permission to participate in the study and were fully aware of the purpose of the research and the consequences for them in taking part. In this research, informed consent was gained from teachers and head teachers from the participant schools before collecting the data. Confidentiality, according to De Vos et al. (2005) is the principle of allowing people not only to talk in confidence, but also to refuse to allow publication of any material that they think might harm them in any way. Anonymity ensured the protection of the participants' right to privacy and confidentiality.

To ensure ethical considerations, all the respondents were made to understand that no participants' names were going to be used or written on the questionnaire and for the sake of anonymity; letters of the alphabet and numbers were used instead. The names of the schools were also not written, to protect participants' identities. The purpose of the study was again stressed for the participants to feel at ease before and during all the sessions. Individuals or groups providing the information were also assured of confidentiality and that the results would be used only for the purpose of the research. No information would be linked to a specific individual or group of people. Permissions were asked for before the use of a tape recorder during the interview sessions. The participants were finally promised that they could have access to the findings of the study, if they wished.

\section{Discussions of Findings}

The analysis of the data revealed themes that emerged from the interview with the teachers on the strategies they use in helping pupils with reading difficulties. From the analysis, some of the strategies that emerged were the use language experience approach, phonemic awareness, peer tutoring, comprehension instruction, reading aloud, and motivation.

Per the strategies teachers use in helping pupils with reading difficulties, the focus group interaction with the teachers revealed that the strategies teachers used assist pupils with reading difficulties to improve on their reading skills. A remark made by a teacher attested to this:

Sometimes when the children come to school, I use their experiences around their environment to teacher them. For example, I ask them questions on what they have seen on their way to school. In describing what they have seen, I then write them on the board and guide them to read them. (A response from a teacher in school C)

Another teacher said this:

As for me I take the children through a lot of things and one of them is I asked the pupils' to describe things and as they describe them, I then write them on the board for them to read. Those who can't read I guide them and this forms part of their reading materials in class (A response from a teacher in school A).

30 Consortia Academia Publishing (A partner of Network of Professional Researchers and Educators) 
One teacher also had this to say:

In my class because we don't have enough materials so I always ask the children to describe their homes, friends and things they see around them. In describing them, I then write their descriptions on the board and then later use them to form some sentences for them to read (A response from a teacher in school B).

The interaction above from the teachers indicated that teachers use the language experience approach to help pupils with reading difficulties to improve on their reading skills and this supports the findings of Ashton-Warner (1965) and Stauffer (1970) that the language experience approach is based on children's language and experiences (as cited in Boison, 2008). Also, Tompkins (2001) noted that, in the language experience approach, children dictate words and sentences about the experiences, the teacher writes down what the children say, and the text they develop becomes the reading material. Walker (2008) added that the language experience approach is a technique used for beginning reading instruction in which the child dictates a story to the teacher. The story becomes the text for instruction, and a collection of the stories becomes the child's first reader (Walker, 2008).

The analysis of data from the focus group discussion indicated that teachers use the phonemic awareness as a strategy to assist pupils with reading difficulties to improve on their reading abilities. A teacher noted this:

I take the children through sounds of the letters because knowing the sound of the letters will let them quickly put these sounds together to form words (A response from a teacher in school B).

Another teacher also said this:

Most of the children in my class cannot read well, so I always take them through the sounds of the letters before we do the actual reading. For example, ask them to identify the number of sounds in a word "ship" so they will have [sh], [i] and [p] and putting them together they will get the word ship (A response from a teacher in school B).

One other teacher also commented this way:

At the lower class, I always take the children through sounds of the letters and help them to use them to form two to three letter words. For example, [c], [a] and [t] gives cat, [c], [a] and [p] gives tap (A response from a teacher in School C).

The analyses of data from the teachers agreed with the findings of Adler (2001) that phonemic awareness is the ability to notice, think about, and work with the individual sounds in spoken words. To Adler, before children learn to read prints, they need to become aware of how the sounds in words work. To him, children must understand that words are made up of speech sounds or phonemes. Also, Boison (2008) affirmed that instruction in phonemic awareness improves children's ability to read words. It also improves their reading comprehension. To Boison, phonemic awareness instruction aids reading comprehension primarily through its influence on words reading. In the author's opinion, for children to understand what they read, they must be able to read words rapidly and accurately. According to her, rapid and accurate word reading frees children to focus their attention on the meaning of what they read.

The analysis revealed that teachers use peer tutoring as a strategy in helping pupils with reading difficulties to improve on their reading skills. For example, a teacher noted this:

I make the good readers to assist those with difficulties with their reading. I normally group them and let the good readers be in charge of the groups to guide them to read and it is helping me a lot doing reading (A response from a teacher in school A). 
Another teacher stated this:

I use peer tutoring by bring pupils who are good in reading to help those who are slow or not good at all, so that they can also help them to read. The pupils are many in the class and I cannot have time for all of them, but through the support of the good ones, I am able to attend to every child in the class because their colleagues are around to assist them (A response from a teacher from school B).

The analyses from the teachers' interaction during the focus group interview supports the findings of Frederickson and Cline (2002) that peer tutoring is a practice that can allow classroom teachers to cater for diverse needs within an inclusive context and there is a wide range of studies supporting its effectiveness. Peer tutoring and cross-age tutoring are instructional methods in which students help each other to learn and, in turn, learn by teaching. One child acts as the tutor while the other is the learner or tutee. Peer tutoring involves learners of the same age helping their peers. This approach has well documented academic and social benefits for both the tutor and the learner (Fuchs and Fuchs, as cited in Hayford, 2013). It has also been shown to improve self-esteem and social interactions (Bagley \& Mallick, as cited in Hayford, 2013).

From the analyses of the focus group interaction, it seemed clear that teachers take pupils through comprehension instruction to help them understand the reading, as noted:

During comprehension reading I put children in group, ask them to predict the topic, discuss it and even guide them to narrate the passage in their own in order to know their understanding on it (A teacher's response from school A).

Another teacher attested to this:

At the upper class level, we do a lot of reading comprehension simply because it is the stage pupils are to read for understanding, so anytime we are doing reading I make the children to discuss the topic, predict the title, ask them questions base on what they read to see if they understood the reading (A response from a teacher in school $\mathrm{C}$ ).

The interaction indicated that teachers use comprehension instruction to help pupils with reading difficulties, as noted by one of the teachers:

At the upper class we do a lot of reading comprehension simply because it is the stage pupils are to read for understanding, so anytime we are doing reading I make the children to predict the topic, ask them questions base on what they read to see if they understood the reading. (A response from a teacher in school C).

This interaction confirms the findings of Mercer and Mercer (2005) that a comprehension instruction is an active process that enables the learner to understand the word being read. To them, a purposeful and thoughtful interaction with text is a good comprehension strategy. These authors also listed other strategies that appear to have a solid scientific basis: comprehension monitoring which involves checking on whether the text read is understood; cooperative learning which involves students working on clearly defined reading tasks in small groups; use of graphic and semantic organizers such as maps, webs, graphs, charts, clusters or frames; questions which deal with students answering and teacher feedbacks; generating questions which involve students scanning the text and asking questions prior to the actual reading; recognizing story starters through story structures; and summarizing skills were synthesis of important ideas and concept in a text are noted.

The analysis of the data revealed that teachers use reading aloud in helping pupils with reading difficulties, as a teacher remarked:

When we are doing reading, I first take the children through the key words by guiding them to 
explain them and form some short sentences with them. After that, I do first and second reading for them. Looking at time available, I sometimes called them one after the order to read to the whole class after which I explain the whole passage and give them some exercise base on the passage (A response from a teacher from school B).

Another teacher attested to this:

At the lower class, we do more reading aloud by reading short sentences and picture reading from books and pictures on the board. So I always read aloud for the children to read after me but sometimes I make the good readers to read to their colleague to read after them and this is helping the children (A response from a teacher from school C).

It seemed clear from the focus group interaction that the teachers took children through reading aloud to enable them to improve on their reading skills. This result confirms the findings of Franzese (2002), who found that read aloud is when children listen to an adult read different types and genres of texts and then engage in talking about the book. Laveaultettal (2003) found that, in read-aloud(s), the teacher reads to the whole class or to a small group, using material that is at the listening comprehension level of the children. The content may focus on a topic related to a curriculum expectation in another subject area, such as mathematics, science, or social studies.

It is recommended that reading aloud be used as a teaching routine in every class, especially in classes which include students with reading difficulties (Razinski \& Padak, 2000).

On motivation as a strategy for helping pupils with reading difficulties. One teacher explained this:

In the process of the reading, those who are able to read well particularly those making good efforts are been praised like; very good, well done, keep it up and the rest (A remarked this from school A).

Another teacher also said this:

I motivate my children by praising them, awarding extra marks to those who make extra efforts to read. I also sometimes give free exercise books and pencils to motivate those that are not good at reading but always try to make way during reading (A response from a teacher from school B).

The analyses of the focus group discussion data revealed that teacher use motivation to encourage children with reading difficulties to read. The finding supports the results of The National Reading Panel (2000), which found motivation as a complex of interrelated social and emotional dimensions that influence children's choices to engage in reading

The analysis of data revealed that teachers used language experience approach, phonemic awareness instruction, peer reading, comprehension instruction, reading aloud and motivation in helping pupils with reading difficulties to improve on their reading skills.

The analysis of the questionnaire indicated that majority (76\%) of the teachers agreed that they take children through letter-sound association and letter-sound correspondences to assist them to read. From the analyses above, it was revealed that taking children through the sounds of the letters assists them to gain letter sound knowledge and correspondence in working with the individual sounds in spoken words during reading. This finding affirms the findings of Adler (2001) that phonemic awareness is the ability to notice, think about, and works with the individual sounds in spoken words. To Adler, before children learn to read prints, they need to become aware of how the sounds in words work. To him, children must understand that words are made up of speech sounds or phonemes. 
Again, the results of a study by Boison (2008) also suggested that phonemic awareness instruction improves children's ability to read words. It also improves their reading comprehension. According to Boison, phonemic awareness instruction aids reading comprehension primarily through its influence on words reading and the ability to understand what they read. Furthermore, majority of the teachers $(82 \%)$ agreed that they assist children to take notes and engage in other activities that will help them remember the content that they are reading. It seemed clear that teachers readily take pupils with reading difficulties through scaffolding activities to assist them to improve on their reading skills. These results are in line with the results of Fournier and Graves (2002), who found that scaffolding reading, help students to take notes, complete graphic organizers, and engage in other activities that will help them remember the content that they are reading. Also, one such activity would be to fill in a matrix of key ideas contained in the text. To them, the teacher can provide hints by partially filling in some of the details as a means to differentiate instruction to meet individual students' needs.

Thirty-seven (74\%) of the teachers agreed that they took children through small groups activities to help them to read. The analyses above showed that the teachers used comprehension strategies to help pupils with reading difficulties to read and understand the words they read. This is because through comprehension instruction, children get the opportunity to work in small groups, predict, answer questions clearly, receive feedback from the teacher, and gain summarizing skills in the content they are reading. These findings agree with the results of a study by Mercer and Mercer (2005), who found that comprehension instruction is an active process that enables the learner to understand the word being read. To them, a purposeful and thoughtful interaction with text and strategic reasoning are good comprehension strategies. These authors also listed other strategies that appear to have solid scientific basis as: comprehension monitoring which involves checking on whether the text read is understood; cooperative learning which involves students working on clearly defined reading tasks in small groups; use of graphic and semantic organizers such as maps, webs, graphs, charts, clusters or frames; questions which deal with students answering and teacher feedbacks; generating questions which involve students scanning the text and asking questions prior to the actual reading; recognizing story starters through story structures; and summarizing skills were synthesis of important ideas and concept in a text are noted.

For instance, out of the 50 respondents in the study, 43(86\%) agreed that they used rewards, praises and other motivation strategies to influence children's choices to engage in reading. This means that the use of motivation arouses pupils' "I can do spirit", arouses their interest, and promotes their active involvement, curiosity and desire to learn in order to improve on their reading skills. This finding reflects the results of The National Reading Panel (2000) that motivation is a complex of interrelated social and emotional dimensions that influence children's choices to engage in reading. In another instance, 35 teachers, representing 70\%, agreed that they read orally a sentence or a phrase to children to read after them.

The analyses proved that reading aloud in class helps pupils to develop love for reading, improve their speaking skills, word recognizing, eye coordination and language skills. This evidence agrees with Rog's (2001) argument that reading stories aloud also means to develop children's "concepts about print, story structure, and other elements of text" and "provides the child with a wealth of information about the processes and functions of written language." Reading aloud to children helps them to develop love of good literature, motivation to pursue reading on their own, and familiarity with a variety of genres, including non-fiction. It provides them with new vocabulary, exposes them to a variety of literature, and contributes to their oral and written language development. Reading aloud should occur every day in the early stage of reading instruction to stimulate the children's interest in books and reading (Laveaultettal, 2003).

The analysis further revealed that 40 teachers, representing $80 \%$, agreed that they involve learners of the same age to help their peers with reading difficulties to read. Also, a study by Fuchs and Fuchs (1998), cited in Hayford (2013), noted that peer tutoring and cross-age tutoring are instructional methods in which students help each other to learn and, in turn, learn by teaching. One child acts as the tutor while the other is the learner or tutee. Peer tutoring involves learners of the same age helping their peers while cross-age tutoring involves students 
Teachers' strategies for teaching pupils with reading difficulties: Awutu Senya East Municipality, Ghana from older classes helping younger children. This approach has well documented academic and social benefits for both the tutor and the learner. The study established that quite a big majority of the teachers seem to agree that they use a lot of strategies in helping pupils with reading difficulties to improve on their reading skills.

\section{Conclusion and Recommendation}

It is concluded that teachers used language experience approach, phonemic awareness, peer tutoring, comprehension instruction, reading aloud, and motivation in helping pupils to improve upon their reading skills. Based on the findings, it is also recommended that more workshops focusing on reading strategies should be organized by the Ghana Education Service for teachers to update existing strategies they use.

\section{References}

Adler, C. R. (2001). Put reading first: The research building blocks for teaching children to read. Centre for the Improvement of Early Reading Achievement.

Baatjies, I. (2003). Reading in South Africa: An overview of policy programmes and campaigns. Innovation, 26, $1-10$.

Boison, C. N. (2008). Preparing children to become good readers. A guide for parents, teachers and pre-school professionals. Department of Special Education, University of Education, Winneba.

Carmine, B. Silbert, J., \& Kame"enui, E. J. (2004). Direct instruction reading (3rd ed.). Merrill/ Prentice Hall.

Creswell, J. W. (2012). Research design: Qualitative, quantitative and mixed methods approach (3rd ed.). Sage Publications.

De Vos, A. S., Strydom, H., Fouche, C. B., \&Delport, C. S. L. (2005). Research at grass roots. For the social science and human services professions (3rd ed.). Van Schaik.

Fisher, D., \& Frey, N. (2012). Improving adolescent literacy: Content area strategies at work (3rd ed.). Pearson.

Fitzpatrick, E., McLaughlin, F., \& Weber, K. P. (2004). The effects of a first day and second day reads on reading accuracy with reading mastery iii text book for a fifth grade student with learning disabilities. International Journal of Special Education, 19(1), 56-62.

Frederickson, N., \& Cline, T. (2002). Special educational needs, inclusion and diversity. Open University Press.

Greef, M. (2005). Information collection: Interviewing. In A. S. de Vos., H. Strydom., C. B. Fouche \& C. S. L. Delport (Eds.), Research at grass roots for the social sciences and human services professionals (3rd ed., pp. 341-374). Van Schaiks.

Guthrie, J. T., Wigfield, Metsala, A., \& Cox, B. (2009). Motivational and cognitive predictors of text comprehension and reading. Scientific Studies of Reading, 3(3), 231-257.

Hayford, S. K. (2013). Special educational needs and quality for all. Department of Special Education, University of Education, Winneba.

Macmillan, J. H., \& Schumacher, S. (2001). Research in education. Harper Publishers.

Mensah, J. A. (2014). Investigating the use of the language experience approach at La Anglican Basic School. Ghana: University of Ghana.

Mercer, C. D., \& Mercer, A. R. (2005). Teaching students with learning problems (7th ed.). Pearson; Merrill/Prentice Hall.

O'Donoghue, T. (2007). Planning your qualitative research project: An introduction to interpretive research in education. Routledge.

Phipps, B. L. (2014). A study of phonics instruction: Teaching phonics dance to at-risk elementary students to improve decoding skills. School of Graduate Studies: Cedarville University. United Kingdom.

Reyner, J. (2008). The reading wars: phonics vs. whole-language. Retrieved from http://jan.ucc.nau.edu/ jar/Reading_Wars.html

Riddell, S., Tisdall, K., Kane, J., \& Mulderrig, J. (2006). Literature review of pupils with additional support needs: Final report to the Scottish executive education department. Journal of Disabilities 34(3), 6-17.

Rohrbeck, C. A., Ginsburg-Block, M. D., Fantuzzo, J. W., \& Miller, T. R. (2003). Peer-assisted learning 
Nsenyiane, A. M., \& Amaniampong, P.

interventions with elementary school students: A meta-analytic review. Journal of Educational Psychology, 95(2), 240-257.

Rowe, M. (2013). Phonics instruction for at-risk third graders: Does it produce higher achievement on the OAA? (Master's Dissertation) College of Education, Ohio University.

Sutherland, K. S., \& Snyder, A. (2007). Effects of reciprocal peer tutoring and self-graphing on reading fluency and classroom behavior of middle school students. Journal of Reading Difficulties, 56(2), 54-78.

Sunjoo, S., K. (2013). The impact of transactional strategies instruction on the reading comprehension of a diverse group of second graders (Doctoral dissertation). University of San Francisco.

Taylor, N. (2007). Literature review educational research for practitioners Nova: Southeastern University.

Temple, C., Ogle, O. Crawford, A., \& Freppon, P. (2008). All children read. Teaching for literacy in today's diverse classrooms. Pearson Education.

The National Reading Panel. (2000). Teaching children to read: An evidence-based assessment of the scientific research literature on reading and its implications for reading instruction. Retrieved from http://www.nichd.nih.gov/pubelications/nrp/report.cfm

Tompkins, G. E. (2001). Literacy for the 21st century: Teaching reading and writing in prekindergarten through grade 4. Merrill/Prentice Hall.

Tournaki, N., \& Criscitiello, E. (2003). Using peer tutoring as a successful part of behavior management. Teaching Exceptional Children, 36(2), 22-29.

Vaughn. S., Gersten. R., \& Chard. D. J. (2000). The underlying message in LD intervention research: findings from research synthesis. Exceptional Children, 67(1), 99-114.

Walker, B. J. (2008). Diagnostic teaching of reading techniques for instruction and assessment (6th ed). Pearson Education.

Wilson. B. (2003). Inclusion: Empirical guidelines and unanswered questions. In D. Mitchell (Ed.), Special educational needs and inclusive education major themes in education (p. 75). Routledge Falmer.

36 Consortia Academia Publishing (A partner of Network of Professional Researchers and Educators) 